\title{
Tobacco Dependence and Control: Individual, Community Approaches and Social Marketing Method
}

\author{
Nazmi Bilir, Hilal Özcebe \\ Hacettepe University, Institute of Public Health, Ankara, Turkey
}

\begin{abstract}
After putting forward the health, social, environmental, economic and other consequences of tobacco use, beginning with developed countries over the last half a century, a number of studies to control tobacco use have been initiated. For this purpose, intervention techniques for tobacco-dependent individuals are being successfully used. However, tobacco control studies should not be just for those people using tobacco. Therefore, apart from the individual approaches enabling people to quit smoking, some social studies should be performed as well. Some of these studies may include the use of medical methods, while others will necessitate legal regulations. With regard to the introduction and implementation of individual and social programs and regulations, social marketing methods should be taken into consideration. In this review, together with information given on individual implementation in the form of the diagnosis and treatment of tobacco dependence to decrease the use of tobacco and legal regulations at the societal level, information about the place and importance of social marketing approaches in this subject is provided.
\end{abstract}

Keywords: Diagnosis of tobacco dependence, social marketing, tobacco control, tobacco dependence, tobacco dependence treatment

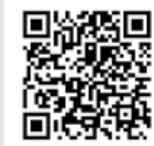

Received date: 01.02 .2013 Accepted date: 21.05 .2013

Address for correspondence

Nazmi Bilir, Hacettepe University, Institute of Public Health, Ankara, Turkey

E-mail: nbilir@hacettepe.edu.tr

(C) Copyright 2014 Turkish Respiratory Society (TRS) DOI: 10.5152/ejp.2014.43925

• Available online at www.eurasianjpulmonol.com

\section{INTRODUCTION}

Tobacco is a product that has been used in traditional societies for centuries; after the period of the Industrial Revolution its use has increased in many countries. The most widely used tobacco product in all societies is cigarettes (1). Nicotine, which is found in cigarettes, is an addictive substance. Although the vast majority of smokers are not happy with smoking, they continue to do so because of their nicotine dependence. Thus, struggle with smoking in fact is a struggle with nicotine dependence $(2,3)$.

To enable people to quit smoking, they must recover from nicotine dependence. On the other hand, making the use of tobacco products difficult via the initiation of legal regulations restricting them is one of the most significant interventions in reducing tobacco use. The prevention of tobacco use in shared areas is among the tobacco control strategies that have been recommended by the World Health Organisation (WHO), since it also provides benefits for non-smokers, preventing them from being exposed to passive smoking $(4,5)$. Consequently, tobacco control studies are approaches protecting both non-smokers and smokers.

\section{Individual Approach in the Struggle against Tobacco Dependence}

For a tobacco-dependent individual to break this dependence is sometimes very easy and sometimes quite hard. There are differences between individuals with regard to dependence levels. Some scales developed for the evaluation of tobacco dependence level are currently in use. The most popular ones among these scales are the Fagerstrom Test for Nicotine Dependence and the Dependence Test of the European Medical Association on Smoking or Health (EMASH) $(6,7)$. In their article, Heatherton et al. (6) explained the questions of the Fagerstrom Test for Nicotine Dependence (FTND) evaluating the number of cigarettes smoked a day and the desire of the individual to smoke. The dependence level is determined by scoring the answers to the questions. A more practical scale was developed by the European Medical Association through the use of two questions from the Fagerstrom Test for Nicotine Dependence (7). Here, an individual smoking 15 cigarettes or more a day is considered to be a high level dependent if they smoke the first cigarette of the day within 30 minutes of waking up. 
After determining the dependence level of a nicotine-dependent individual, they should be given help to break this dependence. For this purpose, a special treatment program has to be planned for every individual. In a systematic (transtheoretical) model developed in 1982 by Prochaska et al. (8), individuals using tobacco products are evaluated in 5 stages with regard to their views and behaviour towards quitting smoking.

a. People who do not plan to quit smoking (pre-contemplation phase): In this phase, the individual does not have a problem with smoking and does not plan to give up smoking within the next 6 months. The negative health, environmental and economic effects of smoking and the gains in case they give up smoking should be highlighted to the individuals in this phase and they must be given support to quit smoking.

b. People who have begun to think about giving up smoking (contemplation phase): These people know the negative consequences of smoking, have begun to give up smoking and are planning to give up within the next 6 months. However there is not yet a plan to quit smoking. While they want to give up smoking, they constantly find excuses to delay it. They should be supported in making a decision regarding giving up smoking.

c. People who are ready or in the preparation phase to quit smoking (preparation phase): The decision to quit smoking by these people is fairly definite and they have decided to do it within the next month. They are expected to set a date and take action without much support, but they may still require additional support.

d. Quitting, trying to quit (action): These people are trying to quit smoking. Less than 6 months have passed since they quit smoking, therefore they are not yet certain that they have given up. They may start smoking again at any time, so they should be monitored closely and supported to prevent that from happening. In this phase, it is important to stay away from the surroundings and behaviours that may encourage smoking.

e. Maintaining not smoking (maintenance): In this group, 6 months or more has passed since the individual gave up smoking and they have adapted to life without cigarettes. The individual is glad that they gave up smoking. However, there is always the risk of relapse, so these people should be attentive and stay away from the surroundings and behaviours that may encourage smoking.

In the individual approach, after determination of the level of dependence of the individual, it is also necessary to identify in which phase the individual is in with regard to the view and behaviour regarding giving up smoking. The progress in the phases identified as five steps should be performed step by step. That is, it will not be right to expect a person who has just started thinking of quitting smoking, to do this immediately. The person should first strengthen his position in this phase and then make preparations for quitting. Then, the person will come to the phase of trying to quit. Some treatment methods can be used as individual approaches for breaking tobacco dependence. The people in the phase of preparation can be helped by certain medications (pharmacological approaches) and psycho-social support approaches (cognitive and behavioual methods) (9-11).

The main purpose of the intervention approaches in behavioural and cognitive areas is to increase the person's motivation to quit smoking. To establish empathy in this approach is very important.
In this way, the points considered important for the person himself are understood and then an attempt is made to correlate this with smoking. For instance, the person may not be worried about his or his wife's health but he may pay attention to his child's health if his child becomes ill frequently. In these interviews, it is necessary to allow the person to speak as freely as possible and identify the problems. With regard to the solutions, rather than giving advice, it is necessary to make the person think about the issue and develop their own solutions. In the beginning of the interview, information about the dependence level of the person has to be obtained and the phase in which the person is with regard to the desire to quit smoking has to be evaluated. After learning the dependence level and the phase that the person is in, if necessary, both the psycho-social support and the pharmacological treatment plan have to be created according to this information. As for the interviews, one on one or group interviews and phone interviews can be conducted if necessary $(12,13)$.

Pharmacological treatment approaches are also useful for breaking the addiction. There are two types of pharmacological approach for the treatment of nicotine dependence: Nicotine Replacement Therapy (NRT) and medications supporting the desire to quit smoking. Nicotine Replacement Therapy is based on the prevention of possible withdrawal symptoms in people who give up smoking. Since nicotine intake in this way is eliminated, some symptoms, which are known as nicotine withdrawal symptoms, may occur. Not all of those who gave up smoking have these symptoms; however, they may especially occur in people with a high degree of dependence related with nicotine withdrawal. These symptoms are felt more heavily in the first days after quitting smoking. The major nicotine withdrawal symptoms are palpitations, sweating, nervousness, craving for cigarettes, lack of concentration and restlessness. Either these symptoms may not be felt at all or may be experienced at a low level in people taking replacement treatment after quitting smoking. Among the available nicotine products are preparations such as nicotine patches (used by applying to a hairless area of the skin), nicotine chewing gum, nicotine spray, nicotine inhalers and sublingual tablets. The decision about which preparation to use and the appropriate dose should be made after consultation with the doctor; the main determining point about the type of nicotine replacement preparation and the dose is the person's dependence level. Stead et al. (14) suggested that occupation, working and social conditions and the choice of the person should be taken into consideration when making any decision.

There are two preparations in use as medications supporting the desire to quit smoking. One of them is a drug called "Bupropion" which has been used for a long time for the treatment of depression and its supporting role facilitating quitting smoking was realised afterwards. This drug decreases the effect of nicotine by inhibiting the receptors to which nicotine is bound in the body, thus lowering the pleasure taken from nicotine. Those who quit smoking by taking this drug reported feeling less of the nicotine withdrawal symptoms. The other drug (Varenicline) is one which has been specially developed for the purpose of nicotine dependence treatment. Being a nicotinic partial agonist, this drug causes dopamine release in the brain by acting like nicotine. In this way, dopamine release is lower than the levels related to smoking. Consequently, the person's craving for smoking reduces. The people taking this drug also feel the nicotine withdrawal symptoms less. 
It is necessary to act according to medical advice for the usage and dose of the medicine. Also, there are medications such as Nortriptilin, Klonidin, Mekamilamin and Rimonabant, but they are still in the testing stage. If they are proven to be effective for helping patients to quit smoking, they can be used for smoking cessation treatment in the future. In addition to these smoking cessation treatments, intensive studies are ongoing with the aim of developing a nicotine vaccine. The impact of the vaccine is based on providing antibodies against nicotine and thus making nicotine ineffective. In this way vaccinated individuals are prevented from taking pleasure from nicotine or smoking $(12,15)$.

While there are various treatment approaches for quitting smoking and breaking tobacco dependence, a significant majority of smokers can quit smoking on their own, without any support. In fact, more people quit smoking on their own than using medications or with other support. Lancaster et al. (16) suggested that the success in quitting smoking and maintaining it is higher when support approaches with or without medication are employed.

There is no guarantee that any person who quit smoking will not begin smoking again; they can start smoking again at any time. This is called relapse. Lancaster et al. (16) pointed out that $70 \%$ of people who quit smoking as a result of medicine and psycho-social support treatments began to smoke again within one year after quitting. Relapse is more common in people who quit smoking by themselves; it is stated that approximately half of the people (49\%) who quit smoking themselves start smoking again within one week.

According to the results of Global Adult Tobacco Survey conducted in Turkey in 2008, approximately half of smokers (44.8\%) have attempted to give up smoking within the last year; however, only $15.8 \%$ of them succeeded in quitting (17). One in ten people (9.3\%) who quit smoking received medicine treatment. It is known that some characteristics play a role in relapse. Young age, people with a high level of dependence, those who do not feel ready, those who frequently visit smoking areas and those with a low level of education have a higher possibility of relapse. In case of relapse, the most important point is that the person should not give way to despair. A significant majority of smokers successfully quit smoking on attempts 2-4. To prevent relapse and decrease the relapse rate for those who stopped smoking, it is important to maintain contact for a period of time. If the withdrawal symptoms occur in the first days or weeks after the person quits smoking, he should be given help to cope with symptoms (12-14).

It is necessary to explain and discuss the negative impacts of smoking and the benefits of quitting smoking to smokers in interviews either before or after quitting smoking.

The issues known as the 5R Strategies in studies about tobacco control and smoking cessation are (12):

\section{R-1 Relevance:}

The negative aspects of smoking are related to daily cases. The most common application in this aspect is relating with a disease. For instance, if the person or someone who is familiar with him has a disease associated with smoking, this case can be put forward. However, if there is no such disease associated with smoking, the possible relationship some factors such as air pollution, the person's occupation, and workplace conditions and their association with smoking can also be discussed.

\section{R-2 Risks:}

First of all, smoking has serious health risks. These risks are generally known by the patients, but the health risks not known by individuals who are not medical staff or experts should be mentioned. Apart from the health risks, other issues such as the environment, economy and social life, and especially the problems caused by passive smoking, can be discussed.

\section{R-3 Rewards:}

Giving up smoking is a huge success and it should be celebrated. In this aspect, the gains achieved by quitting smoking are put forward. The most important reward is the person's health recovery. In this respect, even putting forward the least little positive development (breath relief, waking up refreshed, tasting food better, etc.) is a good approach. Monetary gain by quitting smoking may also be discussed.

\section{R-4 Roadblocks:}

It should be known that smoking cessation is sometimes a long process and roadblocks can be encountered. In this regard, nicotine withdrawal symptoms are important. Some people may experience these problems seriously and have difficulty coping with them. Even if individuals quit smoking, they may still smoke. These kinds of situations should be understood and the person should not be chastised if this happens. An important problem for women is putting on weight after quitting smoking. Those who quit smoking may put on a few kilograms. It is necessary to explain this beforehand and be prepared for that, and it is also important to be able to solve this without turning it into a problem. In fact, those who are sensitive to this matter can lose the excess weight after some time. Therefore, being careful with nutrition and doing exercise will be the best approach. Smokers in the neighbourhood and among close friends is also an issue that should be taken into consideration.

\section{R-5 Repetition:}

Repeating the supportive approach at all interviews is necessary. An important point about repetition is the possibility of starting over the whole process when relapse takes place. Relapse is a frequent situation in the smoking cessation process. This should be clearly explained to individuals and the cessation process should be repeated without discouragement.

\section{Community Approach in Fighting against the Tobacco Dependence} Beyond having an individualistic characteristic, tobacco dependence is a social problem. Therefore, in addition to individual approaches to solve tobacco dependence, there are also necessary steps to be taken at the societal level. Some of the things that need to be done are related to services and some are in the form of legal regulations $(4,10-12)$. Tobacco use negatively affects the health of both the individual and other people. There are many factors that cause people to start smoking. At the top of this list are: the social norms and attitudes towards smoking, prevalence of smoking behaviour, smoking-related messages in the media, the accessibility of tobacco and the tobacco policy of the country. The existence of these factors affects the frequency of tobacco use in any country $(4,10)$.

If the norms and values of society support smoking, then this causes an increase in smoking frequency. Therefore, first of all, the norms 
and values of society should be developed in a way that will not support tobacco use. For example, the beliefs that smoking shows that men are strong and women are independent may cause an increase in tobacco use. An important factor affecting the norms related to tobacco use is the frequency of tobacco use in society $(4,18-19)$. The higher the rate of tobacco use, the higher the possibility of tobacco use being a more accepted behaviour and the increase of tobacco use in society. Moreover, the high frequency of tobacco use in some parts of society may cause an increase in tobacco use in individuals belonging to those parts of society. For instance, non-smokers working somewhere where the majority of workers are men and smokers may start smoking. Seeing popular people smoking may cause others to start smoking. In particular, it is known that children and youngsters are affected by the behaviour of their parents. It is also known that adolescents are affected by their parents in their childhood and then affected by people in their surroundings, people that they imitate in the media (artists, sportsmen, politicians, models etc.) and their friends. A youngster who wants to enter a group of smokers may think that they should also start smoking to be accepted. Moreover, group members may expect that behaviour from them (20).

Among the leading factors affecting norms related to tobacco use is the media. The images and news in the media supporting or encouraging tobacco use may cause non-smokers in society to start smoking. There are two opposing groups affecting the frequency of images and news in the media regarding tobacco. One of the two groups is tobacco companies. They use different techniques to sell their products, demonstrating their products by advertisement, product promotion and sponsoring various activities. Another important intervention affecting the policy of media related with tobacco is the policy of the government about tobacco promotion in the media. If the government prohibits tobacco promotion in the media, it becomes difficult for tobacco companies to reach society $(21,22)$.

Not only the government's policy about the promotion of tobacco, but also its approach towards the growing, processing, selling and consumption of tobacco, that is from production to consumption, is also important. The approach of the government towards the accessibility of tobacco in general determines the accessibility of tobacco for those at risk. According to Vangeli et al. (19), increasing tobacco product prices makes their accessibility difficult for the young, low-income groups and women.

The government should adopt three different interventions to determine its approach towards tobacco. There is a requirement for interventions preventing non-smokers from starting smoking and preventing them from passive smoking, whilst supporting smokers who want to quit smoking. The adoption of these three intervention approaches lowers tobacco use in the society. The World Health Organisation supports these three approaches in the fight against tobacco use and have realised that it is difficult for countries to struggle with tobacco companies themselves; therefore, they adopted the Framework Convention on Tobacco Control in the General Assembly in 2003. The main purpose of the Framework Convention on Tobacco Control was to accelerate its studies worldwide and, in our country, the aim was to decrease both the demand for and supply of tobacco. It is aimed to reach this goal in various ways, such as informing and warning people, in addition to agriculture and trade policies included in the Convention(4). The existence of legal regulations among community approaches about tobacco control is very important. Tobacco control laws are very important, especially with regard to the implementation of rules and the settlement of norms.

Health institutions and staff have important roles in supporting people wishing to quit using tobacco. Helping a person to quit smoking is the most significant intervention to prevent his health being more significantly affected. It is known that a little intervention by a healthcare worker helps someone to quit smoking. In the article written by Stead et al. (9), it is emphasised that every physician and health staff, in their daily work routine, should learn the patients' smoking behaviours and provide support to those patients wishing to quit smoking. These principles are known as the 5A principles:

a. Ask: At every interview, ask about his/her smoking and evaluate the answer.

b. Advise: Advise the smoker to quit smoking. Here, correct information and accurate advice is important.

c. Assess: Assess the desire of the attempt to quit and grade the reply.

d. Assist: Help him to quit and be supportive.

e. Arrange and follow-up: Follow the patient to support his efforts in attempting to quit smoking.

It is useful to assess some important information during quitting tobacco use:

a. Previous quitting attempts, reasons for failure.

b. Knowing before quitting smoking that the requirement level of the smoker at every cigarette is different.

c. Some practical applications supporting smoking cessation: Setting a date, sharing with the social surroundings, clearing away cigarettes, not drinking alcohol, asking other smokers to not smoke nearby, sharing coping methods with difficult situations, gaining the skills to focus on something else, improving the quality of life, lifestyle changes to reduce stress, engaging in pleasurable activities and learning cognitive strategies to cope with negative emotional states.

d. Determining the situations faced during quitting smoking and developing skills to cope with them.

e. Apart from the provision of social support, social support should be provided by their partner, workmates, friends and other important people during the smoking cessation.

f. Making the person come for control and follow-up after smoking cessation.

\section{Social Marketing Approaches in the Struggle against Tobacco Dependence}

\section{Social Marketing Concept}

Fertman et al. (23) emphasised the significance of social marketing techniques in improving health. Social marketing approaches for protecting from diseases arose during the studies to control non-communicable diseases in particular. Success has been achieved in the struggle against communicable diseases which were frequently seen in societies and have led to lots of deaths in the past. Besides the developments in health service provision, vaccination and the beginning of the use of antibiotics have played an important role in achieving this success. The high level participation of society was due to positive impacts achieved in a short period. The communicable 
diseases declined, whereas non-communicable diseases increased in time; therefore, the struggle against these types of diseases came to the forefront. Besides some medical practices in the struggle against non-communicable diseases, people should make some behavioural changes related to their health. People are not eager to make behavioural changes, so they need to be persuaded. Among the interventions used to persuade people are social marketing approaches.

Marketing techniques have long been used for commercial purposes. The purpose of commercial marketing is to increase sales. Social marketing differs from commercial marketing in its purpose to increase and proliferate an idea or application which is socially correct. Studies to enhance the acceptability of a thought or application are known as social marketing.

The social marketing approach began to be used in the 1950s. However, the applications of the social marketing approach becoming widespread took place in the 1980s and 1990s when people-oriented policies were adopted and proliferated. In these years, chronic diseases began to become widespread in society and protective applications against these diseases came to the agenda. With respect to being protected from chronic diseases, efforts were first made to be protected from heart and lung diseases which were more common and led to many deaths in society. It was necessary to create behavioural change to be protected from these diseases. Among the protective approaches considered under the concept of health promotion are interventions such as quitting smoking and bad habits, exercising regularly, and obeying the rules of healthy nutrition. It was benefited from social marketing techniques to a large extent through protection programs from chronic diseases. The first application examples in the health field, which were started in Australia in 1988, are the anti-smoking campaign and the sun protection campaign against skin cancer.

Consequently, the social marketing method aims at behavioural change in the target groups. These changes may be in the form of quitting an existing behaviour (a smoker quitting smoking), changing a behaviour (drinking two litres of water or more a day) as well as in the form of acquiring a new behaviour (folic acid fortification in pregnancy).

\section{Social Marketing Approach in Tobacco Control}

This approach has been used successfully for a long time. The aim of social planning studies in tobacco control can be identified as progressing the smokers a few steps on the basis of the transtheoretical model defined by Prochaska. The first examples began in Australia; having seen that they were successful, social marketing applications in tobacco control were also used in other countries. Additionally, in order for the social marketing studies to be successful, they should be done repetitively and continuously. Moreover, with regard to maintaining its continuity, sufficient financing is important (24).

Social marketing studies for tobacco control in Australia between 1997 and 2004 were successful. The vast majority of smokers (99\%) stated that they found the information given during the campaign to be true, and half of them stated that the campaign supported them quitting smoking. During the campaign period, the rate of smoking decreased from $22.9 \%$ to $19.4 \%$ (25). Also during the campaign, there were anti-smoking advertisements, a smoking cessation hotline was promoted widely, smoking cessation support services were developed, including general practitioners and pharmacists, and a website was established. It is stated that the government's support in close relationship with non-governmental organisations, being competent experts of those included in the program, powerful advertisement campaigns and the smoking cessation services being widespread and accessible are important.

In order to perform a successful social marketing study in tobacco control, a comprehensive program related to the issue should be created (26):

a. In this program, a situation analysis and evaluation first has to be made. In this stage, the legal infrastructure about tobacco control, the attitude and behaviour of society about tobacco use and control and the resources from which support can be provided have to be evaluated.

b. In the second stage, a policy about tobacco control has to be determined. For this, the legal infrastructure should first be prepared and the existing regulations should be updated. Moreover, it is necessary to control the implementation of the law, making efforts for the application to become widespread, to control the tobacco sales points, to cancel the licenses of those not obeying the terms of sale, to prohibit the use of tobacco within a certain distance to health and education institutions and official buildings; i.e. an environment against smoking in society has to be created.

c. In the third stage, which is the social marketing stage, effective messages against smoking should be given in various media organisations, some smoke-free activities (game, entertainment, festival, show etc.) should be organised, it is necessary to cooperate with the local governments and non-governmental organisations, there should be more smoking cessation services in health institutions and this should be widely announced.

d. In the last stage, the results of these studies should be evaluated and shared with the public.

In the social marketing studies about tobacco control, the legal regulations, implementations and their positive results should be publicised.

\section{The Situtation in Turkey}

The tobacco control law was created in Turkey in 1996; it was amended in 2008 and smoking was banned in all indoor places, including the catering sector. Considering the possible reactions from the catering sector, an intensive media campaign was conducted. At the beginning, broadcasts about the benefits of freeing indoor places from smoke were made; in time, programs about the harms of smoking and benefits of quitting were made. These were made possible by the article of the tobacco control law obliging television channels broadcasting for at least 90 minutes per month about the harms of smoking and benefits of quitting. As a result of these broadcasts, an anti-smoking attitude among society was developed. In various studies and in the Global Adult Tobacco Survey, it is suggested that more than $90 \%$ of society developed an anti-smoking attitude (17).

In addition to the television broadcasts, a number of education programs were conducted by experts, for managers of the catering sector and for members of the Provincial Tobacco Control Council; these were formed by the law and its applications. Many education programs were also provided for different parts of society and the health 
staff in particular, and a lot of articles were published by newspapers and magazines. The Media Communication Board was formed within the body of the Health Ministry and social marketing activities were planned at meetings by the participation of experts and officials. Meanwhile, a smoking cessation hotline was established and the call number of the hotline was publicised widely.

Consequently, in tobacco control, there is a need for interventions in three main areas: "preventing starting", "quitting" and "protection from passive smoking". At the base of these three interventions lies the formation of the individual's behaviour. As for the smoking behaviours of individuals, it is known that rather than the individual factors, societal factors play a more important role. In order to minimise the negative impacts of society on the individual, the image that smoking is a negative behaviour should be placed in society. In addition to the interventions of informing the individuals, the messages affecting the attitudes and behaviours in line with the new lifestyle of society should be given throughout life. The use of social marketing approaches also provides benefits for studies in this field to achieve success.

Peer-review: Externally peer-reviewed.

Author Contributions: All authors contributed equally to the preparation of this manuscript.

Conflict of Interest: No conflict of interest was declared by the authors.

Financial Disclosure: The authors declared that this study has received no financial support.

\section{REFERENCES}

1. Seydioğulları M. History, production, trade and basic policies of tobacco in Turkey and around the World. In: Aytemur et al. ZA, Akçay Ş, Elbek O. Tobacco and Tobacco Regulations 2010; 10: 3-20.

2. Kanıt L, Keser A. Biophysiology of tobacco dependency. In: Aytemur ZA, Akçay Ş, Elbek O. Tobacco and Tobacco Regulations 2010; 10: 141-56.

3. Benowitz NL, Hukkanen J, Jacob P. Nicotine chemistry, metabolism, kinetics and biomarkers. Handb Exp Pharmacol 2009; 192: 29-60.

4. WHO. MPOWER. Policy package to reserve the tobacco epidemic. ISBN: 9789241596633.

5. Wilson LM, Avila TE, Chander G, Hutton HE, Odelola OA, et al. Impact of tobacco control interventions on smoking initiation, cessation, and prevalence: a systematic review. J Environ Publ Health.

6. Heatherton TF, Kozlowski LT, Frecker RC, Fagerström KO, et al. Fagerstrom test for nicotine dependence: a revision of the fagerstrom tolerance questionnaire. Br J Addict 1991; 86: 1119-27.
7. European Medical Association Smoking or Health (EMASH). Guidelines on smoking cessation for general practitioners and other health professionals. Monaldi Arch Chest Dis 1997; 52: 282-4.

8. Prochaska JO, DiClemente CC, Velicer WF, Rossi JS. Standardized, individualized, interactive, and personalized self-help programs for smoking cessation. Health Psychol 1993; 12: 399-405.

9. Uzaslan E. Tobacco cessation methods. STED 2003; 12: 166-171.

10. Stead LF, Lancaster T. Combined pharmacotherapy and behavioural interventions for smoking cessation. Cochrane Database Syst Rev 2012; 10 : CD008286.

11. Batra A. Treatment of tobacco dependence. Dtsch Arztebl Int 2011; 108:555-64.

12. European Network for Smoking and Tobacco Control. European Smoking Cessastion Guideliness. 2012. http://www.ensp.org/sites/default/files/ENSP-ESCG_FINAL.pdf

13. Williams RJ, Herzog TA, Simmons VN. Risk perception and motivation to quit smoking: a partial test of the Health Action Process Approach. Addict Behav 2011; 36: 789-91.

14. Stead LF1, Perera R, Bullen C, Mant D, Hartmann-Boyce J, Cahill K, et al. Nicotine replacement therapy for smoking cessation. Cochrane Database Syst Rev 2012; 11: CD000146.

15. Hartman-Boyce J, Cahill K, Hatsukami D, Cornuz J. Nicotine vaccines for smoking cessation. Cochrane Database Syst Rev 2012; 8: CD007072.

16. Lancaster T, Stead LF. Self-help interventions for smoking cessation. Cochrane Database Syst Re 2009;2:CD001118. DOI: 10.1002/14651858. CD001118.pub2. http://www.thecochranelibrary.com/userfiles/ccoch/file/ World\%20No\%20Tobacco\%20Day/CD001118.pdf.

17. WHO. Global Adult Tobacco Survey, 2008. Turkey Report, Ministry of Health 2010.

18. Hiscock R, Bauld L, Amos A, Fidler JA, Munafò M. Socioeconomic status and smoking: a review. Ann NY Acad Sci 2012; 1248: 107-23.

19. Vangeli E, Stapleton J, Smit ES, Borland R, West R. Predictors of attempts to stop smoking and their success in adult general population samples: a systematic review. Addiction 2011; 106: 2110-21.

20. Özcebe H. Cigarette as a deadly product. 6th Cigarette and Health National Committee, 20-22 June 2012, Erzurum, Turkey. Pages 47-50.

21. Durkin S, Brennan E, Wakefield M. Mass media campaigns to promote smoking cessation among adults: an integrative review. Tob Control 2012; 21: 127-38

22. Bala M, Strzeszynski L, Cahill K. Mass media interventions for smoking cessation in adults. Cochrane Database Syst Rev 2008; (1): CD004704.

23. Fertman $\mathrm{CL}$, Allennsworth DD. Social marketing: health promotion programs. Environmental Health Department. Ankara 2011; 57-87.

24. Center for Excellence in Indigenous Tobacco Control. What do we know about the success of social marketing in tobacco control. Access date: 10.01.2012. available at: www.ceitc.org.au.

25. Autralian Government. The National Tobacco Campaign. Access date: 10.01.2012. available at: www.quitnow.info.au.

26. Ministry of Health Promotion. Comprehensive Tobacco Control, Guidance Document, Ministry of Health Promotion. Canada, 2010. 